\title{
Humeanism about Laws of Nature
}

\author{
Harjit Bhogal $^{*}$ \\ Forthcoming in Philosophy Compass
}

\begin{abstract}
Humeanism about laws of nature is, roughly, the view that the laws of nature are just patterns, or ways of describing patterns, in the mosaic of events.

In this paper I survey some of the (many!) objections that have been raised to Humeanism, considering how the Humean might respond. And I consider how we might make a positive case for Humeanism. The common thread running through all this is that the viability of the Humean view relies on the Humean having an importantly different conception of explanation to the anti-Humean.
\end{abstract}

Humeanism, as that term is typically understood in modern metaphysics and the philosophy of science, is the idea that there are no necessary connections between distinct existences. Facts about redness can be necessarily connected to facts about scarletness, because redness and scarletness are not distinct existences. Similarly facts about a whole can be necessarily connected to facts about it's parts, because they are not distinct. But two wholly distinct existences cannot be necessarily connected.

${ }^{*}$ Thanks to Nina Emery, Mike Hicks, Tyler Hildebrand, Elizabeth Miller and Erica Shumener for very helpful comments on previous drafts. 
Humeanism about laws of nature is an approach to scientific laws which denies that laws imply necessary connections between distinct existences. Roughly, the idea is that laws of nature reduce to the patterns of occurrent, non-modal, events that occur in the world. The laws of nature are just patterns, or ways of describing patterns, in the mosaic of events. So, there is no problem with necessary connections between the laws and particular events, since the laws and the particular events are not distinct existences.

(Candidate laws of nature are things like Schrödinger's equation, or the law of conservation of energy. Whether there are laws of nature about higher-level sciences, like biology or economics, is an interesting question that we will put aside.)

The Humean view stands in opposition to anti-Humean views which typically claim that laws are over and above the patterns of events and, in fact, that the laws govern those events, rather than merely describing them. (Although not all anti-Humean approaches think of laws as this separate, governing entity. SeeHildebrand (2020) for an excellent survey of anti-Humean approaches.)

To be more precise, Humeanism about laws of nature is the view that the laws of nature reduce to the Humean Mosaic - that is, the intrinsic physical state of each spacetime point (or each pointlike object) and the spatio-temporal relations between those points - and that the Humean Mosaic is not further reduced to anything else. ${ }^{1}$

(From this point on I'm going to use 'Humeanism' to refer to Humeanism about laws of nature and not the more general denial of necessary connections.)

In principle there are many different possible ways that this reduction of the laws to the Humean mosaic could go, but in practice there is one dominant Humean approach - the

\footnotetext{
${ }^{1}$ This formulation is from Bhogal (fort), it's closely related to those given by Maudlin (2007, p. 51-52) and Lewis (1986, p. x).
} 
Best System Account (BSA). The core idea of the BSA is that the laws are the axioms of a system that best balances simplicity and informativeness. A system is simple if its axioms are simple. A system is informative if it tells us a lot about the mosaic.

There is huge amount more to say about the details of the BSA. How exactly do we define simplicity and informativeness? Does there need to be some restrictions on the language that axioms are formulated in? How do we balance simplicity and informativeness? Are there any other virtues of systems that are relevant to which is best? And so on. Many variants of the BSA have been proposed. ${ }^{2}$

These issues deserve their own article. In this article I'll be putting aside these issues with the BSA to focus on more general issues to do with Humeanism, but I will assume that some version of the BSA is the correct Humean story.

My focus in this article will be different. Humeanism faces a lot of powerful objections. Many of which threaten to be fatal. (And I say this as a committed Humean, by the way.) I'm going to consider some of these objections. It turns out that it's not at all easy for the Humean to respond. But, I'll suggest, if the Humean has a clear conception of how explanation works on their view - that is of how Humean laws can explain particular facts - then this could point the way to responses. I'll end by considering some issues about the positive case for Humeanism - even if Humeanism can be defended from the objections, why should we believe it?

\footnotetext{
${ }^{2}$ E.g. Hicks (2018), Dorst (2019b), Jaag and Loew (fort), Hall (2012), Bhogal and Perry (2017), Loewer (2012), Cohen and Callender (2009), Braddon-Mitchell (2001), Schrenk (2006) etc.. In fact, the BSA machinery can be used by non-Humeans too. Humean BSAs reduce the laws to the Humean mosaic, which does not contain any necessary connections. But,Demarest (2017) uses the BSA to reduce the laws to a base which does include necessary connections.
} 


\section{The Case against Humeanism}

I'll consider four objections to Humeanism. One important objection that I will not consider is the objection that Humeanism is in tension with the non-local 'entanglement' phenomenon of quantum mechanics. These issues have already been discussed in detail in Philosophy Compass (Miller, 2016; Chen, 2019).

\subsection{Explanatory Circularity}

Perhaps the most common objection to Humeanism in recent years is that it leads to a kind of explanatory circularity. The objection goes like this: Laws have an important role in explanation — they are part of what explain specific events. For example, if one billiard ball hits a second the physical laws are part of what explains why the second billiard ball moved. But, on the Humean view, the laws are explained by the patterns of events - via the BSA. So it looks like the laws (partially) explain the particular events, which in turn explain the laws - an unacceptable circularity.

A complex dialectic flows from this objection - let's trace one strand of it.

Step 1: We can respond to the circularity objection by distinguishing between two types of explanation - metaphysical and scientific. We can then claim that Humean laws scientifically explain particular events in the Humean mosaic while they are metaphysically explained by the mosaic. So, there isn't any problematic circularity — what initially looked like circular explanation is just two different explanatory relations running in different directions. This is the suggestion of Loewer (2012).

(Exactly how to distinguish metaphysical from scientific explanations is not wholly clear. Roughly speaking, metaphysical explanations are closely related to, or 'backed' by, ground- 
ing, constitution, or other 'building' relations. Scientific explanations typically don't have such features. The issue is not simple though because, as we will see imminently, grounding or constitution-based explanations do seem to have roles to play in science.)

Step 2: Lange (2013) argues that there is a 'transitivity principle' connecting scientific and metaphysical explanation: If A (partially) metaphysically explains B and B (partially) scientifically explains $\mathrm{C}$ then A (partially) scientifically explains C. He claims that this principle is suggested by scientific practice. Consider, for example, a Newtonian explanation where facts about the mass distribution of an object explain facts about its center of mass, and then the facts about the center of mass explain why that object tipped over. This is a scientific explanation that consists in chaining together a metaphysical explanation of the object's center of mass with a scientific explanation of the why the object tipped over. Lange claims that in general we can chain scientific and metaphysical explanations in this way.

If the transitivity principle is true, then Loewer's response to the circularity objection doesn't work. The claim that the laws are metaphysically explained by the mosaic, while events that make up the mosaic are scientifically explained by the laws implies, given the transitivity principle, that mosaic scientifically explains the events that make up the mosaic. And consequently, particular events in the mosaic partially scientifically explain themselves. This seems unacceptable.

Step 3: Some philosophers, e.g. Hicks and van Elswyk (2015), Miller (2015) and Marshall (2015), argue, in response to Lange, that the transitivity condition is false. They present a series of counterexamples, but perhaps the most compelling ones come from cases of multiple realizability. Imagine that A (partially) metaphysically explains B, and B scientifically explains C. However, A is not necessary for B. Rather, B could have been metaphysically explained in many other ways. In some such cases it seems like A doesn't make a difference 
to the occurrence of $\mathrm{C}$, and so $\mathrm{A}$ isn't explanatorily relevant to $\mathrm{C}$.

For example, Miller (p. 1322) considers a case where a particular particle in a room having a certain kinetic energy partially metaphysically explains the temperature in the room. And in turn the temperature in the room partially scientifically explains why a drop of condensation ran down a glass with velocity v. But the kinetic energy of the particle is not a differencemaker for the velocity of the condensation, and so it not explanatorily relevant.

Step 4: Even assuming that such cases are counterexamples to the transitivity principle (though Lange (2018) denies this), there clearly are some cases where we can chain together scientific and metaphysical explanations to form a bigger scientific explanation. So, the Humean needs some story about why chaining occurs in some cases, but not in the cases that cause a problem for the Humean response to the circularity objection. Dorst (2019a) and Bhogal (fort) both claim that the key is for the Humean to identify the differing aims of scientific and metaphysical explanation. Bhogal claims that scientific explanations are distinctively unificatory, so metaphysical explanations can chain with scientific explanations only in the cases where the metaphysical explanations contribute to unification. Dorst has a similar approach but instead of unification he focuses on the pragmatic role of scientific explanation and the way it 'increase[s] the predictive utility of our scientific theories'.

So the explanatory circularity objection has pushed Humeans towards much bigger claims about the nature of explanation and how the projects of scientific and metaphysical investigation relate.

This is only one strand of the dialectic, but hopefully it gives the reader a feel for the issues. The initial circularity objection could be approached in completely different ways too. The approach we have been considering distinguishes the way in which the laws explain the events making up the mosaic from the way in which those events explain the laws. But you 
could also just deny one of these explanations.

For example, Hicks (fort) (following Ruben (1990) and Skow (2016)) simply denies that laws explain particular events. Rather, laws 'back' scientific explanations of particular events. This removes the initial circularity but there's a concern that the view still accepts something worryingly close to explanatory circularity — that laws are explained by the mosaic and laws 'back' explanations of the mosaic (see Lange (2018, section 4)).

And Miller (2015, section 3), Marshall (2015) and Kovacs (2020) suggest that we can respond by simply denying that the laws are metaphysically explained by the mosaic. This certainly avoids the circularity, but it's a difficult question whether the resulting view really counts as Humean and would be satisfying to those with Humean inclinations. The strategy is deny the laws are metaphysically explained by the mosaic but to accept that the laws supervene on the mosaic. Whether this really counts as a Humean view gets at some much bigger questions about how to formulate metaphysical theses, and in particular whether modality is the right tool in formulating them. (See Bhogal (2017, section 4) for a discussion of different ways to formulate Humeanism.)

\subsection{Non-SuperVENIENCE}

Another classic objection to Humeanism is that it implies that the laws supervene on the mosaic, but this seems to be false - there seem to be possible situations, taken seriously in scientific practice, where the mosaic can be the same but the laws can differ. Tooley (1977, p. 669), Carroll (1994, pp. 57-67) and Maudlin (2007, pp. 67-68) give commonly discussed examples, but here's a very simple case: Take a mosaic $M$ which only contains one particle moving inertially though spacetime. This mosaic is consistent with the laws of Newtonian mechanics. So, it seems like there would be a world with this mosaic where the 
laws are Newtonian. But the mosaic is also consistent with it being a law that everything always moves inertially. So, it seems like there could be a world with this mosaic where a law is that everything moves inertially. But now it seems like there are two possible worlds where the mosaic is the same but the laws are different. So supervenience is false.

Humeans have had surprising little to say about cases like this. The most common response is to say that one, or both, of the worlds described above are in fact metaphysically impossible. More generally they accept that their view goes against our intuitions about what worlds are possible. (See Earman and Roberts (2005, section 2), Loewer (1996, pp.192194), Roberts (1998, p. 428-433), Beebee (2000, sections 5-6) etc..)

Roberts (2008, pp. 358-361) and Bhogal (fort, section 2.3) have more substantial responses though. Roberts claims that the world with mosaic $M$ where the laws are Newtonian and the world with mosaic $M$ where the law is that particles always move inertially both exist and the are the same world. This is because he has a non-standard conception of law where claims about a particular law holding in a possible world are context sensitive. ${ }^{3}$ So, there is only one world which has mosaic $\mathrm{M}$, but in some contexts it's true that the laws of that world are Newtonian and in other contexts it's true that the laws of that world include the proposition that everything always moves inertially.

Bhogal claims that the we can extend Loewer's distinction between scientific and metaphysical explanation to a distinction between metaphysical and scientific possibility. ${ }^{4}$ In particular, he thinks that there is good reason for the Humean to accept that there is an important space of possibility that outruns metaphysical possibility - the space of scientific possibility contains worlds that are not metaphysically possible. The central thought is that the expla-

\footnotetext{
${ }^{3}$ Carroll (2018) develops Roberts's approach, giving a different account of how the context sensitivity works.

${ }^{4} \mathrm{He}$ actually uses the term 'nomothetic' rather than 'scientific'.
} 
nation of the laws in terms of the mosaic is a metaphysical explanation but is not relevant for scientific practice — and so that explanation constrains the space of metaphysical possibility but not scientific possibility. As a result, he claims that both the mosaic $\mathrm{M}$ worlds are scientifically possible, even though at least one has to be metaphysically impossible.

Both of these responses are somewhat complicated. But they share an idea: That the Humean needs to, in some way or other, loosen the modal connection between the laws and the mosaic. They need to allow that there are, in some sense, possibilities where the laws can vary independently of the the mosaic. However, in order for the view to remain distinctively Humean, this modal claim needs to be made consistent with the claim that the laws are reduced to the mosaic. Roberts does this by making the reduction of the laws to the mosaic context sensitive. Bhogal does this by distinguishing between multiple spaces of possibility. Perhaps there are other potential strategies too. But the challenge is to loosen the the modal connection in a way that's well motivated and consistent with Humeanism.

\subsection{The Regularity of The World, and Induction}

This section is actually about two, very closely related, objections which have had surprisingly little attention in recent years.

Here's the first objection. Given the Humean view that there are no necessary connections between distinct existences the fact that the world is relatively regular and orderly seems like a complete fluke - a gigantic coincidence. If every event in the Humean mosaic is disconnected then it's incredibly surprising that those events would form regular patterns. (Strawson, 1989, p. 24) makes this case using an analogy:

[Imagine that] a true randomizing device determines the colour value of each 
pixel on a standard $800 \times 400$ computer screen, running on a ten-times-asecond cycle - so that each pixel can take any colour value for each $1 / 10$ th second period. On the screen it appears that there is a film showing. A woman enters a house, walks over to a stove, and puts on a kettle. Life - a world, as it were - goes on in an ordered, regular fashion, exactly as regularly as in our own world. But the image is being generated by the true randomizing device. It is pure fluke that what happens on the screen appears to tell a coherent story of a regular, ordered world, rather than filling up with - or suddenly switching to - a fizz of points of colour.

This, Strawson thinks, is analogous to the Humean picture of the world. If each event in the Humean mosaic is a disconnected pixel, so to speak, then we should expect the world to consist in random chaos. It's a massive coincidence that we, in fact, see order in the world. The second objection is closely related: If it's just a fluke that the world we have observed has been ordered and regular then it seems that we are not justified in thinking that the world will continued to be ordered in the future. So, we are not justified in making inferences from what has happened in the past to what will happen in the future. And so, Humeanism leads to inductive skepticism.

These two objections could be developed in a couple of different ways. Firstly, via probabilistic considerations: The regularity of the world is a fluke for the Humean because, if we count up the possible Humean mosaics, there are many more Humean mosaics that are chaotic than ones which are regular (e.g. Foster (1982), Hildebrand (2013), Filomeno (ming)). Secondly, via explanatory considerations: The regularity of the world is a fluke for the Humean because there is no explanation of the regularity (e.g. Emery (2019)). The explanatory versions of the problems are, I think, more forceful than the probabilistic 
versions. In response to the claim that there are more chaotic Humean mosaics than regular ones the Humean could reasonably respond that this is no special problem for them - if anti-Humean laws can be arbitrarily complicated then there are more chaotic anti-Humean worlds than there are regular ones. (Although, whether this Humean response works may depend upon the exact version of anti-Humeanism they are targeting, see Hildebrand (2013, fort).)

This doesn't defuse the explanatory versions of the objection though. It's still the case that there seems to be no explanation of the regularity of the world for the Humean — it's merely a coincidence - and that this seems to undermine inductive inferences.

What responses can the Humean give here? Here are three possible options:

(1) The Humean could accept that they have a problem here but to claim that the antiHumean has a problem too. Beebee (2011) makes this case with respect to induction. She accepts that the Humean position has a problem with induction, but suggests that everyone has a problem with induction. However, whether or not Beebee really shows that the Humean and the anti-Humean are really in an equal position with respect to induction, it's hard to see how this can help with the concern that the Humean can't explain the regularity of the world.

(2) Another option is for the Humean to say that they do, in fact, have an explanation of the regularity. It's somewhat hard to see what this explanation could be though. Perhaps the most natural suggestion is that the Humean laws explain the regularity of the world. So, for example, if it happened to be the case that the best system of the world outputted Newtonian laws, like F=MA, then those laws would explain the regularity of the world just like they would, according to the Humean, explain all sorts of other facts about the mosaic. But something seems very unsatisfying about the prospect of explaining the regularity of 
the mosaic by appealing to Humean laws which are themselves derived from the mosaic. And the concern here isn't just the circularity concern described in section 1.1, rather it's something deeper.

One way to put the concern is that explanations seem to give us some important epistemic benefit - explanations help us to understand the phenomenon in question. But, how could the Humean law that $\mathrm{F}=\mathrm{MA}$ - that $\mathrm{F}=\mathrm{MA}$ is part of the best system for summarizing the mosaic in a simple and informative way - possibly help us understand why the mosaic is regular? How does citing the output of the BSA give us any epistemic benefit in investigating why the mosaic is regular in the first place? Let's come back to these issues more in the next subsection.

(3) A third option is for the Humean to accept that they cannot explain the regularity of the world, but to somehow argue that this is acceptable — that the regularity of the mosaic is appropriately unexplained. And the regularity being appropriately unexplained, somehow, helps make sense of why it's reasonable to expect the regularity to continue and so reasonable to perform inductions. ${ }^{5}$

This, I suspect, is the best path forward for the Humean, but it's not at all easy to see how it could be developed properly. What would be needed is some story about why it is ok for the Humean to not explain certain facts about the mosaic. This story would have to flow from a more general understanding of when facts need explaining and when they do not a understanding of when it is appropriate for theories to take certain facts as explanatorily basic and when those facts must be explained. I'll come back to this issue briefly in the next section.

In fact, all of these options seem extremely difficult for the Humean to properly develop,

\footnotetext{
${ }^{5}$ Hicks (fort, section 3.2) suggests an approach of roughly this kind, though in the context of responding to a slightly different objection than the one we are considering.
} 
but if some such response isn't developed then the objection that the regularity of the world is just an incredible coincidence looks to be fatal for Humeanism.

\subsection{What is Humean Explanation?}

A lot of the discussion so far points towards a very deep problem for the Humean - one that is rarely addressed head on in the literature: It's extremely unclear what the Humean conception of explanation is.

This may initially seem puzzling. Can't the Humean just look at the literature on explanation and pick out whatever their favorite theory of explanation is? After all, there are many options to choose from.

Just for simplicity, imagine that the Humean favored some kind of covering-law approach to explanation - on this view we explain an event by showing how it follows from the laws and certain background conditions. ${ }^{6}$ Why is it then unclear what the Humean conception of explanation is?

Strevens (2008, section 1.23) distinguishes between two elements that any good theory of explanation have. A good theory has to specify formal criteria which explanations have to meet in order to really count as explanation. He calls this the formal requirement. But, in addition, good theories have to specify the 'The relation between explanation and explanandum that the account claims gives an explanation its force'. He calls this the explanatory relation. Another way to get at (roughly) the same issue is to ask what it is about the explanation that makes sense of why the explanandum holds? How does the explanans allow us to understand the explanandum?

\footnotetext{
${ }^{6}$ Of course, more has to be said here for the view to avoid classic problems with the D-N account of explanation. But that's not important now.
} 
The problem is that the Humean can search the literature on explanation and pick their favorite account of the formal requirement, but the associated explanatory relation might well look very different when the account is integrated with the Humean metaphysical picture.

For example, when an anti-Humean accepts the covering-law account of explanation it's natural for them to suggest that what gives such explanations their force is the way that the explanandum depends upon the explanans. On a typical anti-Humean view the law governs particular events, making those events happen. The anti-Humean can say that the force of covering-law explanations come from tracking these real nomic dependence relations that exist in the world.

But the Humean does not think that there are real nomic dependence relations. They cannot say that the force of explanations comes from the way that the laws govern the events. Rather, they need some other story about the force of those explanations. This issue is surprisingly underexplored in the literature. The Humean needs a clear story about the force and value of scientific explanations. If they don't have that then the Humean has an inadequate picture of how science works.

The Humean response that I favor here is, in a sense, a very natural one. The basic idea was suggested briefly by Loewer (1996, p. 197) and Miller (2015, p. 1326) - the force of Humean explanation should derive from unification. When we explain a particular event by appealing to a Humean law what we are doing is showing how this particular event fits into a more general pattern in the mosaic — we are unifying this event with other events in the mosaic.

This appeal to unification does, I think, help the Humean with some of the objections that we have considered. As I mentioned in the section on explanatory circularity, the appeal to unification can help us draw the distinction between metaphysical and scientific explanation 
— the aim of scientific explanation is unification, not so for metaphysical explanation and so it can make sense of when scientific and metaphysical explanations chain and when they do not (Bhogal, fort). Further, as I mentioned in the section on the non-supervenience objection, once we have properly drawn this distinction in explanation it's plausible that we can extend this to a distinction between scientific and metaphysical possibility, giving us tools to deal with the non-supervenience objection.

And further, it's possible that the appeal to unification will help make sense of why certain general facts about the mosaic are legitimately unexplained for the Humean. After all, if the force of explanation comes from fitting particular events into more general patterns, in order to unify the event in question with other events, then it's natural to think that the most general patterns in the mosaic must be unexplained. So, perhaps we could argue that the unificationist conception of explanation motivates the appropriateness of taking these general patterns as unexplained.

So, developing a unificationist approach to Humean explanation is, I think, very promising. But, the details of the unificationist approach to explanation are sparse. Friedman (1974) and Kitcher (1981) influentially developed the initial versions of unificationist approach, but subsequently, the view has dropped in popularity and so hasn't been filled out in the way that one would hope. It remains rather impressionistic. If the Humean wants to appeal to unification, as I think they should, there is a lot of work to do.

\section{The Positive Case}

As I noted earlier, most of the literature on Humeanism consists in developing the view and responding to the variety of objections that it faces. There is less work on motivating the 
view. Part of the reason for this, I suspect, is that many people find the Humean view obviously attractive. The basic picture that Humeanism gives us, where the world consists of events just pushed up against each other in spacetime, is very compelling to those philosophers who like desert landscapes and sparse ontology. The implicit thought among many is that if the Humean view is defensible then its clear attractions should lead us to accept it. But, if we try to go further than this in developing a positive reason to be Humean, then we start to see that things are not simple.

In particular, the most natural motivation for Humeanism comes from general empiricist ideas. The basic thought is that anti-Humean laws, if they were to exist, would be undetectable. And that's a reason to believe that they don't exist.

In slightly more detail, the thought is that there is some set of evidence that we have in a privileged way via our experience; there is certain evidence that we have directly, or noninferentially. And anti-Humean laws are underdetermined by this data. After all, the experiences that we have are consistent with many different sets of anti-Humean laws, and indeed, with the lack of anti-Humean laws (Earman (1984)). One way to put the point, very much in the spirit of Hume himself, is that it seems like we only directly experience parts of the Humean mosaic - we do not directly experience the necessary connections that may or may not be there. Further, the anti-Humean laws are underdetermined by the Humean mosaic, so they are underdetermined by our experience. And, the thought continues, the anti-Humean laws being underdetermined by our direct evidence is reason to suspicious of their existence.

As Maudlin (2007, Chapter 2) argues, the concern with this kind of empiricist reasoning is that it seems to overgeneralize. Very similar considerations can be raised against the existence of entities that are simply too small to be directly observed, like electrons, and in favor of 
views where entities like electrons don't exist, but the observable world just looks as if they do. And in fact, we can run similar empiricist arguments for even more general anti-realist positions. When we start on the train of empiricist reasoning is hard to see how to get it to stop.

The most obvious way of getting the empiricist train to stop is via explanatory considerations. We have to commit to the existence of electrons in order to explain what we directly observe. This seems like a very promising approach. But of course, it's natural for the antiHumean to say the same thing about laws — we have to appeal to anti-Humean laws in order to explain what we observe. In order to explain, for example, the regularity of the world. So the Humean must resist the idea that anti-Humean laws are essential for explaining facts about the mosaic while accepting that electrons, for example, are essential explainers. Once again the issue comes down how the nature of explanation differs for the Humean and the anti-Humean.

This empiricism is not the only possible motivation for Humeanism of course. One common motivation comes from the way that the defender of the BSA claims that their view mirrors scientific practice (e.g. Demarest, 2017). The BSA sticks very closely to the actual practice of science - in fact, one way to describe the view is that it takes the actual methodology of science and it mirrors that methodology in the account of the metaphysics of laws. Hall (2012) calls this the 'unofficial guiding idea' behind Humeanism about laws. Perhaps this mirroring of science favors the Humean view. But the concerns expressed in the sections on explanatory circularity and non-supervenience suggest that the Humean view in fact diverges significantly from the claims of explanation and possibility that we see in scientific practice. It's not clear, then whether it is the Humean or the anti-Humean that properly respects scientific practice. 
Maybe the most common motivation for Humeanism that you hear in person is that there is just something very strange about anti-Humean laws that govern particular events. What even is governing? It is true that the anti-Humean should say more than they traditionally have about the nature of concepts like governing. ${ }^{7}$ But clearly, such a motivation for Humeanism isn't dialectically effective against anti-Humeans who don't find anything strange in governing laws.

Of course, this isn't a comprehensive survey of the possible motivations for Humeanism. But we can see that it's not especially clear how to best motivate the Humean view.

\section{Conclusion}

The Humean view of laws faces many difficulties. So many, in fact, that the view might start to seem untenable. But these difficulties are not independent. For example, although it may not seem it initially, the Humean problem with explanatory circularity is related to the problem with inductive skepticism - they are both driven by considerations of how explanation works for the Humean. Consequently, the Humean does have the potential to deal with all these problems. In particular, if Humean can develop a clear conception of the nature of explanation, then that can go a very long way to defending and motivating their view.

\footnotetext{
${ }^{7}$ Though Wilsch (fort) and in progress work by Perry (ms), Shumener (ms), and Emery (ms) shows that some anti-Humeans are taking on this challenge.
} 


\section{References}

Beebee, H. (2000). The Non-Governing Conception of Laws of Nature. Philosophy and Phenomenological Research 61, 571-594.

Beebee, H. (2011). Necessary Connections and the Problem of Induction. Nous 45(3), $504-527$.

Bhogal, H. (2017). Minimal Anti-Humeanism. Australasian Journal of Philosophy 95(3), $447-460$.

Bhogal, H. (fort.). Nomothetic Explanation and Humeanism About Laws of Nature. Oxford Studies in Metaphysics.

Bhogal, H. and Z. R. Perry (2017). What the Humean Should Say About Entanglement. Nô̂s 51(1), 74-94.

Braddon-Mitchell, D. (2001). Lossy laws. Nồs 35(2), 260-277.

Carroll, J. (1994). Laws of Nature. Cambridge University Press.

Carroll, J. (2018). Becoming humean. In W. Ott and L. Patton (Eds.), Laws of Nature. OUP.

Chen, E. K. (2019). Realism about the wave function. Philosophy Compass 14(7).

Cohen, J. and C. Callender (2009). A better best system account of lawhood. Philosophical Studies.

Demarest, H. (2017). Powerful properties, powerless laws. In J. D. Jacobs (Ed.), Causal Powers, pp. 38-53. Oxford, United Kingdom: Oxford University Press. 
Dorst, C. (2019a). Humean laws, explanatory circularity, and the aim of scientific explanation. Philosophical Studies 176(10), 2657-2679.

Dorst, C. (2019b). Towards a Best Predictive System Account of Laws of Nature. The British Journal for the Philosophy of Science 70(3), 877-900.

Earman, J. (1984). Laws of nature: The empiricist challenge. pp. 191-223. Springer Verlag.

Earman, J. and J. T. Roberts (2005). Contact with the Nomic: A Challenge for Deniers of Humean Supervenience About Laws of Nature Part I: Humean Supervenience. Philosophy and Phenomenological Research 71(1), 1-22.

Emery, N. (2019). Laws and their instances. Philosophical Studies 176(6), 1535-1561.

Emery, N. (ms.). The governing conception of laws.

Filomeno, A. (forthcoming). Are non-accidental regularities a cosmic coincidence? revisiting a central threat to humean laws. Synthese, 1-1.

Foster, J. (1982). Induction, explanation, and natural necessity. Proceedings of the Aristotelian Society 83(n/a), 87-101.

Friedman, M. (1974). Explanation and Scientific Understanding. The Journal of Philosophy $71(1), 5-19$.

Hall, N. (2012). Humean Reductionism About Laws Of Nature. Unpublished manuscript.

Hicks, M. T. (2018). Dynamic humeanism. British Journal for the Philosophy of Science 69(4), 983-1007.

Hicks, M. T. (fort.). Breaking the explanatory circle. Philosophical Studies, 1-25. 
Hicks, M. T. and P. van Elswyk (2015). Humean Laws and Circular Explanation. Philosophical Studies 172, 433-443.

Hildebrand, T. (2013). Can primitive laws explain? Philosophers' Imprint 13, 1-15.

Hildebrand, T. (2020). Non-humean theories of natural necessity. Philosophy Compass 15(5), 1-1.

Hildebrand, T. (fort). Individuation and explanation: A problem for dispositionalism. Philosophical Studies, 1-21.

Jaag, S. and C. Loew (fort.). Making best systems best for us. Synthese, 1-26.

Kitcher, P. (1981). Explanatory unification. Philosophy of Science 48(4), 507-531.

Kovacs, D. M. (2020). The oldest solution to the circularity problem for humeanism about the laws of nature. Synthese, 1-21.

Lange, M. (2013). Grounding, scientific explanation, and Humean laws. Philosophical Studies 164, 255-261.

Lange, M. (2018). Transitivity, Self-Explanation, and the Explanatory Circularity Argument Against Humean Accounts of Natural Law. Synthese 195(3), 1337-1353.

Lewis, D. (1986). Philosophical Papers, Volume 2. Philosophical Papers, Volume 2. Oxford: Oxford University Press.

Loewer, B. (1996). Humean supervenience. Philosophical Topics 24(1), 101-127.

Loewer, B. (2012). Two accounts of laws and time. Philosophical Studies 160(1), 115-137. 
Marshall, D. (2015). Humean laws and explanation. Philosophical Studies 172(12), 31453165.

Maudlin, T. (2007). The Metaphysics Within Physics. The Metaphysics Within Physics. New York: Oxford University Press.

Miller, E. (2015). Humean Scientific Explanation. Philosophical Studies 172(5), 13111332.

Miller, E. (2016). Quantum holism. Philosophy Compass 11(9), 507-514.

Perry, Z. R. (ms.). There's nothing in the rulebook that says a dog can't play basketball; two ways the laws of nature might govern.

Roberts, J. (1998). Lewis, Carroll, and Seeing Through the Looking Glass. Australasian Journal of Philosophy 76(3), 426-438.

Roberts, J. T. (2008). The Law-Governed Universe. Oxford University Press.

Ruben, D. (1990). Singular explanation and the social sciences. Midwest Studies in Philosophy 15(1), 130-149.

Schrenk, M. (2006). A theory for special science laws. In H. Bohse and S. Walter (Eds.), Selected Papers Contributed to the Sections of Gap.6. Mentis.

Shumener, E. (ms.). Governance and necessitation.

Skow, B. (2016). Reasons Why. Oxford University Press UK.

Strawson, G. (1989). The Secret Connexion: Causation, Realism, and David Hume. Oxford University Press. 
Strevens, M. (2008). Depth: An Account of Scientific Explanation. Harvard University Press.

Tooley, M. (1977). The Nature of Laws. Canadian Journal of Philosophy 7(4), 667-698.

Wilsch, T. (fort). The governance of laws of nature: Guidance and production. Philosophical Studies, 1-25. 